\title{
Investigations of Platelet Function in Whole Blood with BAPA as Anticoagulant
}

\author{
Josephine Tabea Tauer ${ }^{\mathrm{a}} \quad$ Judith Lohse $^{\mathrm{a}} \quad$ Silvia König $^{\mathrm{b}} \quad$ Ralf Knöfler $^{\mathrm{a}}$ \\ ${ }^{a}$ Hämatologie/ Onkologie, Klinik und Poliklinik für Kinderheilkunde, \\ ${ }^{\mathrm{b}}$ Medizinische Klinik I, Universitätsklinikum Carl Gustav Carus, Dresden, Germany
}

\section{Keywords}

BAPA - Storage time - Platelet function - Whole blood

\section{Summary}

Background: Citrate anticoagulation of blood results in non-physiologically low calcium concentration and rapid deterioration of platelet viability. Benzylsulfonyl-D-ArgPro-4-amidinobenzylamide (BAPA) as anticoagulant maintains the physiological calcium level and seems to retain platelet function (PF) over a time period of at least $24 \mathrm{~h}$. We evaluated PF in BAPA-anticoagulated peripheral whole blood (WB) between 0.5 and $30 \mathrm{~h}$ after blood collection. Methods: In WB from 21 healthy volunteers (15 women, 6 men, age range 19-57 years) platelet aggregation (PA) was determined by impedance method and ATP release by luminometry. Platelet response was tested by ADP (10 and $20 \mu \mathrm{mol} / \mathrm{l}$ ) and collagen ( 1 and $2 \mu \mathrm{g} / \mathrm{ml}$ ) between 0.5 and $30 \mathrm{~h}$ after blood collection. Results: Parameters of ADP-induced PA showed stable values until $6.5 \mathrm{~h}$ after blood collection followed by a significant decline. PA in response to collagen was stable up to $25 \mathrm{~h}$ of storage. ATP release induced by collagen displayed a continuous, significant decrease over time. Conclusion: Preservation of platelet response in BAPAanticoagulated blood depends on the applied agonist showing that collagen-induced PA is more stable compared to ADP known as a weak agonist in WB.

\section{Schlüsselwörter \\ BAPA · Lagerungszeit · Thrombozytenfunktion · Vollblut}

\section{Zusammenfassung:}

Hintergrund: Die Antikoagulation von Vollblut (VB) mit Zitrat führt zu einer erniedrigten Kalziumkonzentration, wodurch die Thrombozytenüberlebenszeit eingeschränkt wird. Benzylsulfonyl-D-Arg-Pro-4-amidinobenzylamid (BAPA) als Antikoagulanz hält die physiologische Kalziumkonzentration aufrecht und scheint eine ausreichende Plättchenfunktion über mindestens $24 \mathrm{~h}$ zu gewährleisten. Wir führten Plättchenfunktionsuntersuchungen in BAPA-antikoaguliertem VB durch, welches im Zeitraum zwischen 0,5 bis $30 \mathrm{~h}$ nach Blutabnahme gelagert wurde. Methoden: In VB-Proben von 21 gesunden Freiwilligen (15 Frauen, 6 Männer, Alter 19-57 Jahre) wurden die Plättchenaggregation (PA) mit Hilfe der Impedanzmethode und die ATP-Freisetzung mittels Luminometrie untersucht. Die PA wurde mit ADP (10 und $20 \mu \mathrm{mol} / \mathrm{l}$ ) und Kollagen ( 1 und $2 \mu \mathrm{g} / \mathrm{ml}$ ) nach einer Lagerungszeit von 0,5-30 h nach Blutentnahme induziert. Ergebnisse: Die Parameter der ADP-induzierten PA zeigten stabile Werte bis zu 6,5 h nach Blutentnahme gefolgt von einem signifikanten Abfall. Die Aggregation in Response auf Kollagen war bis zu einer Lagerung von $25 \mathrm{~h}$ stabil. Die ATP-Freisetzung induziert durch Kollagen zeigte einen kontinuierlichen, signifikanten Abfall. Schlussfolgerung: Die Erhaltung der Plättchenfunktion in BAPA-antikoaguliertem Blut ist abhängig vom verwendeten Agonisten, wobei sich die Aggregation mit Kollagen als stabiler im Vergleich zum schwächer wirksamen Agonisten ADP erweist.

\section{KARGER}

Fax +497614520714

Information@Karger.de

www.karger.com
(C) 2010 S. Karger GmbH, Freiburg

Accessible online at:

www.karger.com/tmh 


\section{Introduction}

Testing of platelet function is essential for the detection of hereditary and acquired platelet function defects. As recently published, light transmission aggregometry (LTA) is the most commonly used method for this purpose in coagulation laboratories of German-speaking countries [1]. However, LTA is a time-consuming and technically challenging method affected by many pre-analytical and analytical variables. For this reason LTA should be performed only in highly specialized laboratories by expert personnel [2].

Sodium citrate is still the most commonly used blood anticoagulant for LTA in platelet-rich plasma (PRP) and for impedance aggregometry in whole blood (WB) [2,3]. It acts by chelating extracellular $\mathrm{Ca}^{2+}$, leading to a decrease in $\mathrm{Ca}^{2+}$ levels in the sample from about 1.2 to $0.1 \mathrm{mmol} / \mathrm{l}$ [4-6]. Due to the fact that platelets are dependent on $\mathrm{Ca}^{2+}$ for normal function, the platelet viability is markedly reduced in citrated blood which is a critical point with respect to the transportation time of samples to the coagulation laboratory [7]. In many laboratories it is the rule that the investigation of aggregometry in PRP and in WB should start 15-30 min after blood collection and must be completed within 3-4 h $[2,3,8,9]$. Within this tight time frame the limited platelet viability in citrate-anticoagulated blood does not allow the shipment of samples from patients with suspected platelet function defects to distant coagulation laboratories for sophisticated analysis.

Anticoagulants that maintain the physiological concentration of divalent cations $\left(\mathrm{Ca}^{2+}, \mathrm{Mg}^{2+}\right)$ in the samples, such as the direct thrombin inhibitor hirudin, seem to be more suitable as anticoagulant for investigations of platelet aggregation $[10,11]$. However, hirudin has also some drawbacks, for instance the weak agonist-induced second wave of the aggregation curve is absent which is an important parameter for detection of platelet function disorders [2]. In addition, analysis of platelet release reaction displays some limitations in hirudin-anticoagulated blood [12-14].

Recently, the synthesis of a new anticoagulant, benzylsulfonyl-D-Arg-Pro-4-amidinobenzylamide (BAPA), was described which acts as dual inhibitor of thrombin and factor $\mathrm{Xa}$ and does not affect the physiological $\mathrm{Ca}^{2+}$ level $[15,16]$. Blood anticoagulation with BAPA is reported to retain platelet function over a time period of at least $24 \mathrm{~h}[5,6]$. Platelet aggregation testing in WB represents an established diagnostic method in some clinical laboratories. In the pediatric setting it has the advantage of the relatively low amount of blood needed. This prompted us to evaluate platelet function in BAPA-anticoagulated WB samples over a time period of $30 \mathrm{~h}$ after blood collection.

\section{Material and Methods}

\section{Blood Collection}

Blood was aspirated by peripheral venous puncture in 21 apparently healthy volunteers (15 females and 6 males; age range 19-57 years; mean age 32 years) who gave their informed consent in accordance with the Ethical Hospital Review Board approval. They had not taken any medication influencing platelet function for at least 14 days before testing. After discharge of the first $3 \mathrm{ml}$ of blood specimens were anticoagulated with BAPA (final concentration $50 \mu \mathrm{mol} / \mathrm{l}$; Thrombovette ${ }^{\circledR}$ Xipla, Probe and Go, Osburg, Germany) and stored until measurement at room temperature $\left(22 \pm 2{ }^{\circ} \mathrm{C}\right)$. Platelet response was measured $0.5,6.5,25$ or $30 \mathrm{~h}$ after blood collection.

\section{Platelet Response Measurement}

Platelet aggregation was determined by impedance method and ATP release by luminometry using a two-channel Chrono-Log lumi-aggregometer (type 560-CA, Chrono-Log Corporation, Havertown, PA, USA) in accordance with the manufacturer's instructions and the description in the literature [17]. Aggregation and ATP release were induced by ADP at final concentrations of 10 and $20 \mu \mathrm{mol} / 1$ and by collagen (type I collagen from equine tendons) at 1 and $2 \mu \mathrm{g} / \mathrm{ml}$. After addition of agonist, aggregation curves were recorded for $6 \mathrm{~min}$. Within this time the maximal aggregation was determined and expressed in ohms $(\Omega)$. ATP release curves were recorded until the peak was reached, and the maximal release was calculated in nmol by adding an ATP standard to a separate sample. Both agonists and the ATP standard were purchased from Chrono-Log Corporation. Parameters of aggregation and ATP release curves were determined by AGGRO/LINK software (Version 4.0; Chrono-Log Corporation).

\section{Statistics}

Data were analyzed using Kolmogorov-Smirnov test to calculate the values for normality. Since all values were normally distributed, paired data were compared using T-test with Holm adjustment of the p values. Any two-tailed probability of the corrected p-value below 0.05 was considered significant. Statistical analyses were performed using SPSS for Windows software, version 17.0.0 (SPSS Inc., Chicago, IL, USA), and diagrams were constructed using GraphPad Software, version 5.0 (GRAPHPAD Software Inc., San Diego, CA, USA).

\section{Results}

\section{ADP-Induced Platelet Aggregation}

Platelet aggregation by ADP at 10 and $20 \mu \mathrm{mol} / 1$ showed a slight, non-significant decline within the time interval from 0.5 to $6.5 \mathrm{~h}(\mathrm{ADP} 10 \mu \mathrm{mol} / \mathrm{l}$ from $14.0 \pm 3.1 \Omega$ to $12.1 \pm 3.7 \Omega$; ADP $20 \mu \mathrm{mol} / 114.5 \pm 2.5 \Omega$ to $13.6 \pm 3.7 \Omega$ ) after blood collection (fig. 1 and 2). For both ADP concentrations a significant decrease of platelet aggregation after $6.5 \mathrm{~h}$ of storage time was shown.

\section{Collagen-Induced Platelet Aggregation}

Statistical analysis revealed that the collagen-induced platelet aggregation at 1 and $2 \mu \mathrm{g} / \mathrm{ml}$ remained stable until $25 \mathrm{~h}$. Thereafter, it displayed a significant decline (fig. 3 and 4). For collagen at $1 \mu \mathrm{g} / \mathrm{ml}(2 \mu \mathrm{g} / \mathrm{ml})$ mean values of $17.9 \pm 2.8 \Omega$ $(18.3 \pm 3.0 \Omega)$ at $0.5 \mathrm{~h}, 16.8 \pm 2.1 \Omega(17.4 \pm 2.6 \Omega)$ at $6.5 \mathrm{~h}$ and $15.8 \pm 4.2 \Omega(17.6 \pm 2.9 \Omega)$ at $25 \mathrm{~h}$ were calculated. 


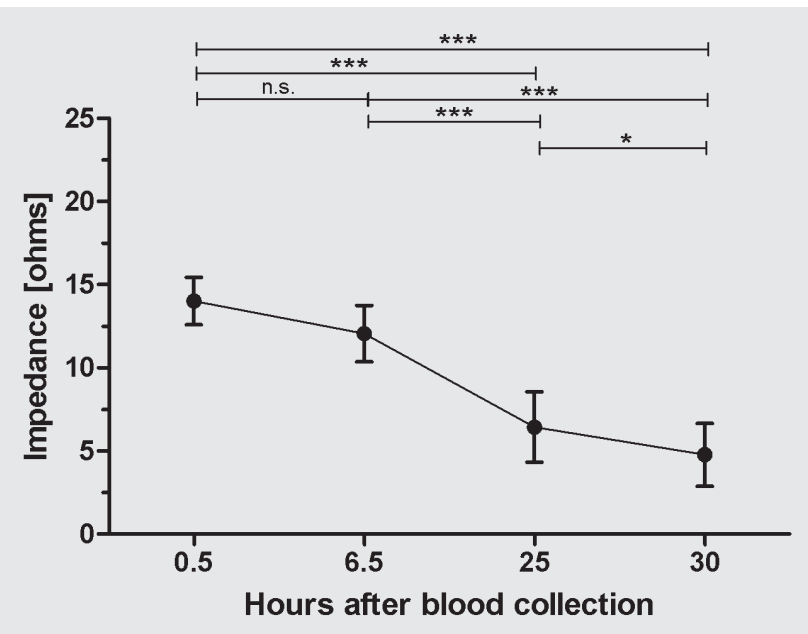

Fig. 1. Platelet aggregation induced by $10 \mu \mathrm{mol} / \mathrm{l} \mathrm{ADP}$ depending on the storage time. Data points represent the mean $( \pm 95 \% \mathrm{CI})$ of 21 individuals. $*$ p $<0.05 ; * * p<0.01 ; * * * p<0.001 ;$ n.s. $=$ not significant.

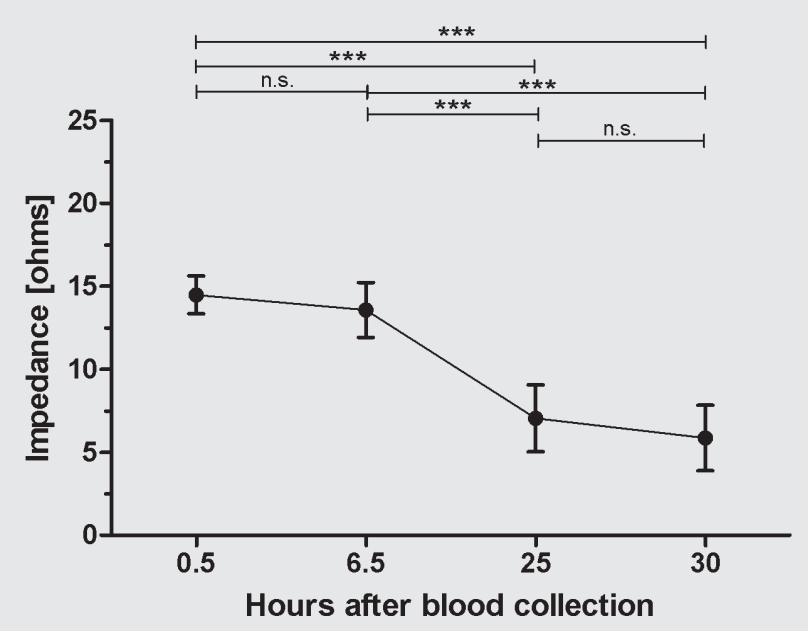

Fig. 2. Platelet aggregation in response to ADP at $20 \mu \mathrm{mol} / \mathrm{l}$ depending on the storage time. Data points represent the mean $( \pm 95 \% \mathrm{CI})$ of 21 individuals. ${ }^{*} \mathrm{p}<0.05 ; * * \mathrm{p}<0.01 ; * * * \mathrm{p}<0.001 ;$ n.s. $=$ not significant.

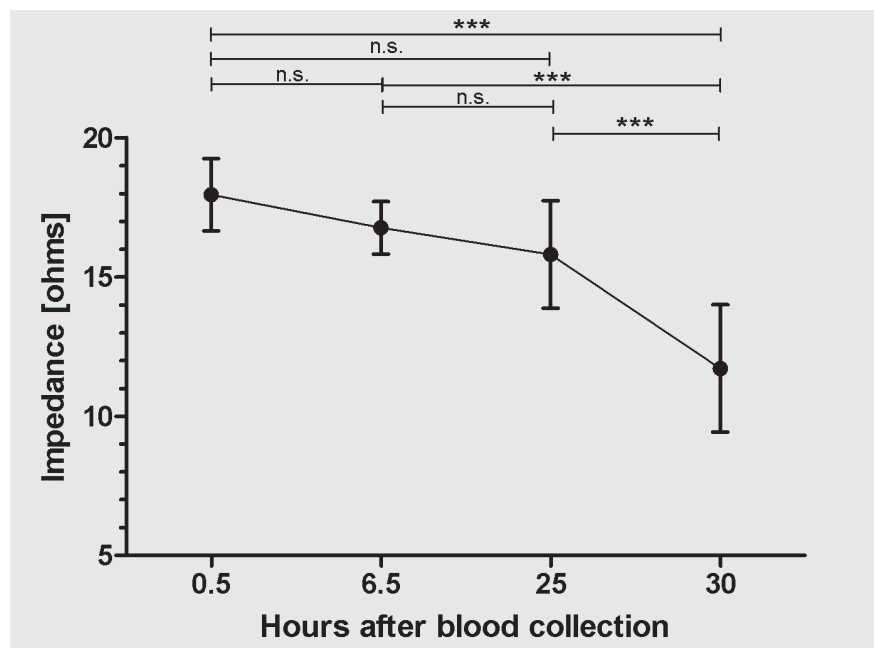

Fig. 3. Platelet aggregation induced by $1 \mu \mathrm{g} / \mathrm{ml}$ collagen depending on the storage time. Data points represent the mean $( \pm 95 \% \mathrm{CI})$ of 21 individuals. $* \mathrm{p}<0.05 ; * * \mathrm{p}<0.01 ; * * \mathrm{p}<0.001 ;$ n.s. $=$ not significant.

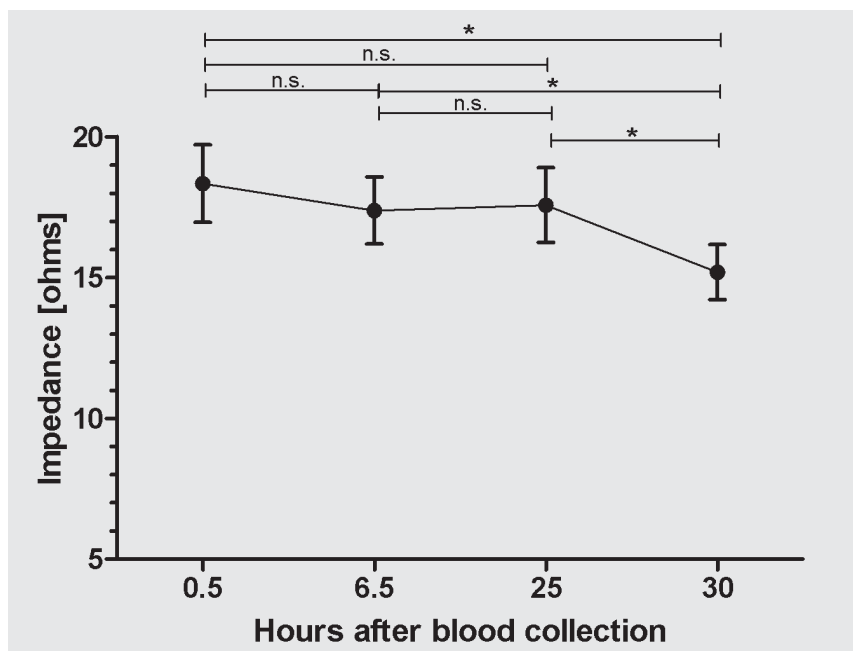

Fig. 4. Platelet aggregation induced by $2 \mu \mathrm{g} / \mathrm{ml}$ collagen depending on the storage time. Data points represent the mean $( \pm 95 \% \mathrm{CI})$ of 21 individuals. $* \mathrm{p}<0.05 ; * * \mathrm{p}<0.01 ; * * * \mathrm{p}<0.001 ;$ n.s. $=$ not significant.

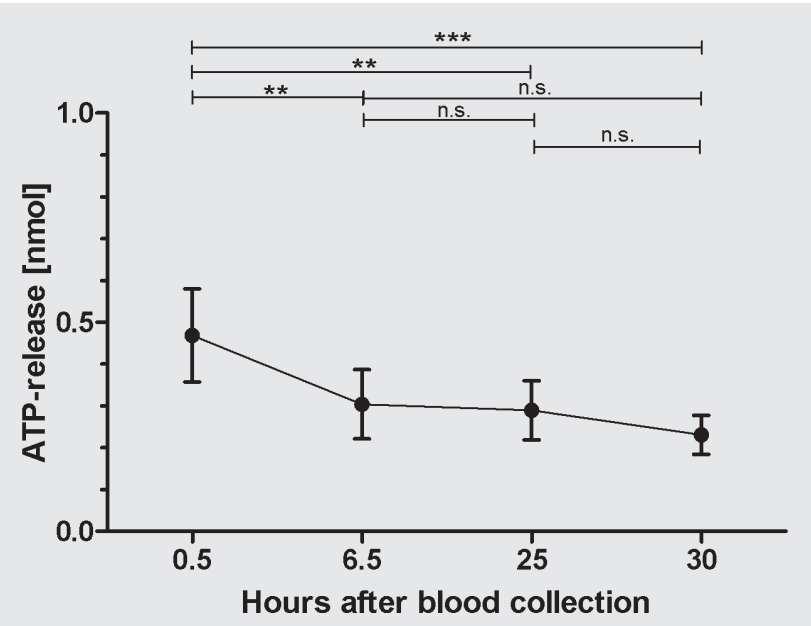

Fig. 5. ATP-release induced by $1 \mu \mathrm{g} / \mathrm{ml}$ collagen depending on the storage time. Data points represent the mean $( \pm 95 \% \mathrm{CI})$ of 21 individuals. $* \mathrm{p}<0.05 ; * * \mathrm{p}<0.01 ; * * * \mathrm{p}<0.001 ;$ n.s. $=$ not significant.

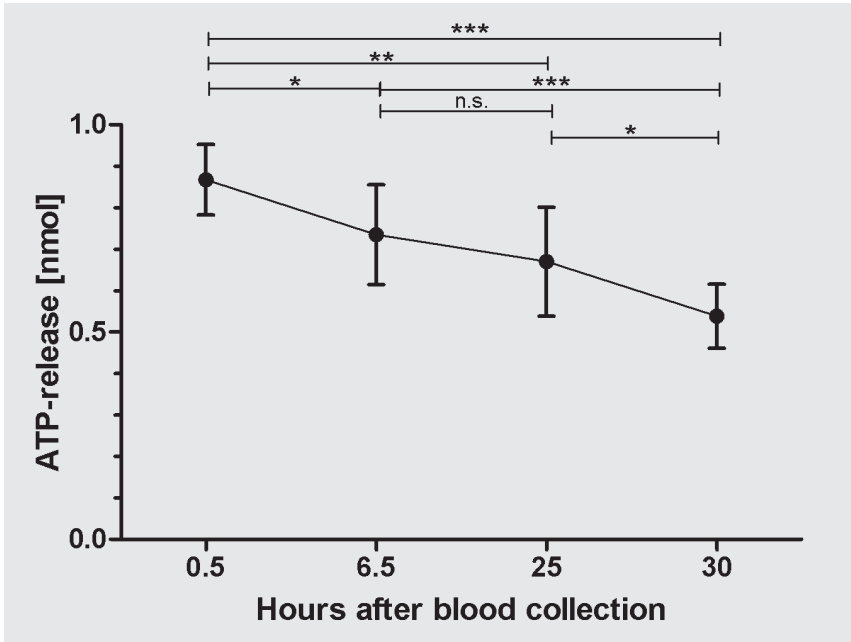

Fig. 6. ATP-release induced by $2 \mu \mathrm{g} / \mathrm{ml}$ collagen depending on the storage time. Data points represent the mean $( \pm 95 \% \mathrm{CI})$ of 21 individuals. $* \mathrm{p}<0.05 ; * * \mathrm{p}<0.01 ; * * * \mathrm{p}<0.001 ;$ n.s. $=$ not significant. 


\section{Collagen-Induced ATP Release}

For the ATP release at both collagen concentrations a significant decrease during the first $6.5 \mathrm{~h}$ (collagen $1 \mu \mathrm{g} / \mathrm{ml} 0.47 \pm$ $0.24 \mathrm{nmol}$ at $0.5 \mathrm{~h}$ to $0.3 \pm 0.18 \mathrm{nmol}$ at $6.5 \mathrm{~h}$; collagen $2 \mu \mathrm{g} / \mathrm{ml}$ $0.87 \pm 0.19 \mathrm{nmol}$ at $0.5 \mathrm{~h}$ to $0.74 \pm 0.26 \mathrm{nmol}$ at 6.5 . h) was detected which was followed by a slow further decline until $30 \mathrm{~h}$ of blood storage (fig. 5 and 6). For collagen at $1 \mu \mathrm{g} / \mathrm{ml}$, ATP release remained stable from 6.5 to $30 \mathrm{~h}$, and for collagen at $2 \mu \mathrm{g} / \mathrm{ml}$ ATP release decreased significantly from 6.5 to $30 \mathrm{~h}$.

\section{Discussion}

Up to now, only a limited number of studies have been published regarding the determination of platelet function in BAPA-anticoagulated blood samples [5, 6, 18, 19]. Here we demonstrate that the preservation of platelet response in BAPA-anticoagulated WB seems to depend on the agonist applied. Platelet aggregation determined by the impedance method induced by collagen which is known as a strong agonist in whole blood was more stable over time compared to ADP being a weak agonist.

Our observations of declining ADP-induced platelet aggregation in BAPA-anticoagulated WB over time are supported by data reported from Kaiser et al. [18] and Hellis et al. [19]. Kaiser et al. [18] revealed a loss of aggregation response to ADP at $5 \mu \mathrm{mol} / 1$ in BAPA-anticoagulated WB between 8 and $12 \mathrm{~h}$. Hellis et al. [19] analyzed ADP-induced platelet aggregation at $6.4 \mu \mathrm{mol} / \mathrm{l}$ in BAPA-anticoagulated $\mathrm{WB}$ and found a significant decrease of platelet response at $12 \mathrm{~h}$ after blood collection compared to the aggregation at $2 \mathrm{~h}$. For ADP at $5 \mu \mathrm{mol} / \mathrm{l}$ in BAPA-anticoagulated PRP they could show a significant decrease within $22 \mathrm{~h}$ after blood collection [19]. These findings are in line with our observation of a decreased platelet response by the weak agonist ADP in a nearly timedependent manner.

These findings differ from two studies which did not detect a significant decrease of ADP-induced aggregation at $10 \mu \mathrm{mol} / \mathrm{l}$ after up to $32 \mathrm{~h}$ of storage [6] and at $6.5 \mu \mathrm{mol} / \mathrm{l}$ after up to $24 \mathrm{~h}$ [5] following blood collection in BAPA-anticoagulated WB. However, our results contrast these findings as the final concentrations of 10 and $20 \mu \mathrm{mol} / \mathrm{l}$ of ADP led to stable aggregation curves for only $6.5 \mathrm{~h}$ after blood collection. As in these two studies also BAPA-anticoagulated WB the impedance method for determination of aggregation and comparable ADP final concentrations were used, but the discrepancies to our results cannot be explained sufficiently. However, it should be mentioned that several methodological variables which are not given in detail in the papers, e.g. the storage conditions of the BAPA-anticoagulated blood, the speed of stirrer in the sample and others, may substantially influence results of aggregation testing.
Concerning collagen-induced aggregation and ATP release, Haubelt et al. [6] demonstrated that both parameters remained stable over a time period of up to $48 \mathrm{~h}$ after blood collection using a final concentration of $5 \mu \mathrm{g} / \mathrm{ml}$ of collagen in BAPA-anticoagulated WB. The authors suggested that anticoagulation with BAPA enables the transport of blood specimens from distant locations for platelet function testing. The same conclusion was drawn by Hellstern et al. [5] who examined platelet function in BAPA-anticoagulated PRP and WB using collagen at final concentrations of 2 and $3.2 \mu \mathrm{g} / \mathrm{ml}$ and demonstrated stable results between 2 and $24 \mathrm{~h}$ after blood collection [5]. Using collagen at 1 and $2 \mu \mathrm{g} / \mathrm{ml}$ we also found stable aggregation curves up to $25 \mathrm{~h}$ of storage time. Thus, the stability of collagen-induced platelet aggregation and ATP release over time in BAPA-anticoagulated samples seems to be influenced by the applied final collagen concentration. The high final collagen concentration of $5 \mu \mathrm{g} / \mathrm{ml}$ seems to retain platelet function in whole blood over a long time period (48 h), but it may be questionable if this concentration may allow the detection of platelet function defects.

The determination of ATP release from platelets displays an important diagnostic tool for the detection of platelet secretion disorders [3]. However, BAPA as inhibitor of thrombin does not allow the determination of thrombininduced maximal ATP release. Taking into consideration, that we found a significant decrease of collagen-induced ATP release already within the first $6.5 \mathrm{~h}$ after blood collection, the determination of ATP release in BAPA-anticoagulated samples seems not to be of use.

Only studies using BAPA-anticoagulated samples obtained from healthy adults have been published so far. Therefore, the application of BAPA in routine coagulation laboratories needs further investigations, and the suitability of BAPA for determination of specific platelet function defects in patients with hereditary or acquired platelet disorders still has to be proven. From our point of view the shipment of samples to distant laboratories is a critical point due to the delay in platelet function testing which has well-known limitations. Therefore, we recommend the shipment of BAPA-anticoagulated blood only for testing of collagen-induced aggregation and in combination with a control sample.

\section{Acknowledgement}

The authors would like to thank E. Kuhlisch (Institute for Medical Informatics and Biometry at the University of Dresden, Germany) for his recommendations to the statistical data analysis.

\section{Disclosure}

The authors declared no conflict of interest. 


\section{References}

1 Streif W, Olivieri M, Weickardt S, Eberl W, Knoefler R: Thromkid - a competence network for functional platelet abnormalities. Results of a population based survey carried out by the pediatric group of the German society of Thrombosis and Hemostasis research (GTH). Transfus Med Hemother 2007;34:56-62.

2 Cattaneo M: Light transmission aggregometry and ATP release for the diagnostic assessment of plate let function. Semin Thromb Hemost 2009;35:158167.

3 McGlasson DL, Fritsma GA: Whole blood platelet aggregometry and platelet function testing. Semin Thromb Hemost 2009;35:168-180.

4 May JA, Heptinstall S: Effects of anticoagulants used during blood collection on human platelet function; in Gibbins JM, Mahaut-Smith MP (eds) Platelets and Megakaryocytes, vol 1. Totowa, Humana Press, 2004, pp 3-11.

5 Hellstern P, Stürzebecher U, Wuchold B, Haubelt H, Seyfert UT, Bauer M, Vogt A, Stürzebecher J: Preservation of in vitro function of platelets stored in the presence of a synthetic dual inhibitor of factor Xa and thrombin. J Thromb Haemost 2007;5: 2119-2126.

6 Haubelt H, Vogt A, Hellstern P: Preservation of platelet aggregation and dense granule secretion during extended storage of blood samples in the presence of a synthetic dual inhibitor of factor Xa and thrombin. Platelets 2008;19:496-501.
Silver WP, Keller MP, Teel R, Silver D: Effects of donor characteristics and platelet in vitro time and temperature on platelet aggregometry. J Vasc Surg 1993;17:726-733.

8 Harrison P: Platelet function analysis. Blood Rev 2005:19:111-123.

9 Sweeney JD, Hoernig LA, Michnik A, Fitzpatrick JE: Whole blood aggregometry. Influence of sample collection and delay in study performance on test results. Am J Clin Pathol 1989;92:676-679.

10 Wallén NH, Ladjevardi M, Albert J, Bröijersén A: Influence of different anticoagulants on platelet aggregation in whole blood; a comparison between citrate, low molecular mass heparin and hirudin. Thromb Res 1997;87:151-157.

11 Belcher PR, Muriithi EW, Day SP, Wheatley DJ: Platelet aggregatory responses to low-dose collagen are maintained in hirudin-anticoagulated whole blood for $24 \mathrm{~h}$ when stored at room temperature. Platelets 2001;12:34-36.

12 Lages B, Weiss HJ: Dependence of human platelet functional responses on divalent cations: aggregation and secretion in heparin- and hirudin-anticoagulated platelet-rich plasma and the effects of chelating agents. Thromb Haemost 1981;45:173-179.

13 Glusa E: Platelet aggregation in recombinanthirudin-anticoagulated blood. Haemostasis 1991; 21(suppl 1):116-120.
14 Glusa E: Hirudin and platelets. Semin Thromb Hemost 1991;17:122-136.

15 Schweinitz A, Stürzebecher A, Stürzebecher U, Schuster O, Stürzebecher J, Steinmetzer T: New substrate analogue inhibitors of factor Xa containing 4-amidinobenzylamide as P1 residue: Part 1. Med Chem 2006;2:349-361.

16 Stürzebecher A, Dönnecke D, Schweinitz A, Schuster O, Steinmetzer P, Stürzebecher U, Kotthaus J, Clement B, Stürzebecher J, Steinmetzer T: Highly potent and selective substrate analogue factor Xa inhibitors containing D-homophenylalanine analogues as $\mathrm{P} 3$ residue: part 2. Chem Med Chem 2007;2:1043-1053

17 Ingerman-Wojenski CM, Silver MJ: A quick method for screening platelet dysfunctions using the whole blood lumi-aggregometer. Thromb Haemost 1984;51:154-156.

18 Kaiser A, Krüger JC, Mügge A, Neubauer H: Extension of the storage time of blood samples for impedance aggregometry tests without a reduction of diagnostical validity by using a synthetic dual inhibitor of factor Xa and thrombin. Hamostaseologie 2010;30:A84 (abstract P10-14).

19 Hellis M, Mani H, Lindhoff-Last E: Improvement in stability of platelet function testing using BAPAor hirudin anticoagulated blood. Hamostaseologie 2010;30:A91 (abstract P12-21). 